\title{
Chronic Blockade of Endogenous Atrial Natriuretic Polypeptide (ANP) by Monoclonal Antibody against ANP Accelerates the Development of Hypertension in Spontaneously Hypertensive and Deoxycorticosterone Acetate-Salt-Hypertensive Rats
}

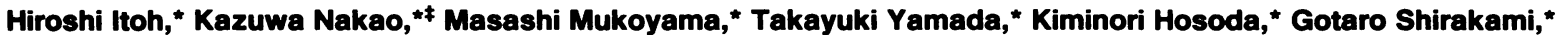 \\ Narito Morii," Akira Sugawara," Yoshihiko Saito," Shozo Shiono," Hiroshi Arai, " Ikuyo Yoshida," and Hiroo Imura* \\ ${ }^{*}$ Second Division, Department of Medicine, Kyoto University School of Medicine, Kyoto 606, Japan; ${ }^{\ddagger}$ Radioisotope Research Center, \\ Kyoto University, Kyoto 606, Japan
}

\begin{abstract}
To explain the pathophysiological significance of endogenous atrial natriuretic polypeptide (ANP) in the development of hypertension, we examined the effect of chronic, repetitive administrations of MAb raised against $\alpha$-rat ANP in two rat models of hypertension, spontaneously hypertensive rats of the stroke prone substrain (SHR-SP), and deoxycorticosterone acetate (DOCA)-salt rats. Weekly intravenous administrations of MAb with high affinity for $\alpha$-rat ANP, named KY-ANP-II (MAb[KY-ANP-II]), started at the age of $6 \mathrm{wk}$, significantly augmented the rise in blood pressure of SHR-SP, compared with control SHR-SP treated with another MAb with quite low affinity for $\alpha$-rat ANP, named KY-ANP-I (MAb[KY-ANP-I]), throughout the observation period. The administrations of MAb[KY-ANP-II] had no significant effect on blood pressure of age-matched normotensive Wistar Kyoto rats, compared with those receiving MAb[KY-ANP-I]. Weekly administrations of MAb[KY-ANP-II] also significantly aggravated hypertension in DOCA-salt rats. Blood pressure of DOCA-salt rats treated with MAb[KY-ANP-II] was significantly higher than that of DOCA-salt rats treated with MAb[KY-ANP-I] throughout 8 wk of DOCA and 1\% saline administration. The administration of MAb[KY-ANP-II] also significantly attenuated exaggerated diuresis and natriuresis in DOCA-salt rats compared with those treated with MAb[KY-ANP-I]. Elevated plasma cGMP levels of both SHR-SP and DOCA-salt rats were significantly reduced by the administration of MAb[KYANP-II]. These results suggest the compensatory role of augmented secretion of ANP in these hypertensive rats and support the concept that augmented secretion of ANP could represent an antihypertensive deterrent mechanism.
\end{abstract}

\section{Introduction}

The pioneering discovery that atrial extracts possess potent diuretic and natriuretic activities (1) was followed by subse-

Address all correspondence and reprint requests to Dr. K. Nakao, Second Division, Department of Medicine, Kyoto University School of Medicine, 54 Shogoin Kawahara-cho, Sakyo-ku, Kyoto 606, Japan.

Received for publication 16 May 1988 and in revised form 17 January 1989.

J. Clin. Invest.

(c) The American Society for Clinical Investigation, Inc.

0021-9738/89/07/0145/10 \$2.00

Volume 84, July $1989,145-154$ quent identifications of atrial natriuretic polypeptide (ANP) ${ }^{1}$ in human and rat atria (2-4). It has been recognized that ANP is synthesized in the cardiac myocyte and secreted into the blood stream through the coronary sinus (5), in response to extracellular volume expansion (6-8) via the stretch-secretion coupling mechanism $(3,4)$. In many cardiovascular and endocrine disorders associated with elevated cardiac filling pressure, the plasma ANP level is increased (5, 9-11).

Exogenously administered ANP induces not only diuresis and natriuresis, but also relaxation of vascular smooth muscles and inhibition of renin, aldosterone, and vasopressin release in animals and in humans $(3,4,8,11)$. Until now, however, the information on the pathophysiological significance of circulating ANP has been scarce. Whether ANP functions at circulatory levels encountered under physiological perturbations or pathophysiological conditions has not been resolved, mainly because of a lack of a specific inhibitor for ANP.

Several laboratories, including ours, have reported that plasma ANP levels are elevated both in patients with essential hypertension and secondary hypertension due to hyperaldosteronism or renal hypertension $(12,13)$, and in several hypertensive animals, including spontaneously hypertensive rats (SHR) and its substrain, SHR-stroke prone (SHR-SP) (14-16), and deoxycorticosterone acetate (DOCA)-salt rats $(17,18)$. In addition, we have recently explained augmented gene expression of the ANP gene in the ventricle, as well as in the atrium in SHR and SHR-SP at the stage of hypertension and ventricular hypertrophy $(19,20)$. These findings suggest that augmented secretion of ANP plays a compensatory role in the maintenance of blood pressure. In addition, an infusion of ANP (5-100 ng/kg per min) for a couple of days to a week caused a reduction in blood pressure in SHR; rats with onekidney, one-clip or two-kidney, one-clip renal hypertension; or angiotensin II- or norepinephrine-infused rats $(21,22)$, without consistent changes in urine volume or urinary excretion of sodium. In patients with essential hypertension, a bolus injection $(50-100 \mu \mathrm{g})$ or an infusion $(1 \mu \mathrm{g} / \mathrm{min})$ of relatively high doses of ANP caused rises in urine volume and sodium excretion and a fall in arterial pressure $(23,24)$. However, the extent to which increased levels of endogenous ANP participate in the modulation of hypertension has not been clarified yet.

Recently, we have produced two kinds of high-affinity MAbs against $\alpha$-ANP, a circulating, 28-amino acid form of ANP named KY-ANP-I and KY-ANP-II $(25,26)$. KY-ANP-I

1. Abbreviations used in this paper: ANP, atrial natriuretic polypeptide; DOCA, deoxycorticosterone acetate; SHR, spontaneously hypertensive; SP, stroke prone; WKY, Wistar Kyoto rats. 
is specific for $\alpha$-human ANP ( $\alpha$-hANP) but not for $\alpha$-rat ANP $(\alpha$-rANP), whereas KY-ANP-II recognizes $\alpha$-hANP and $\alpha$ rANP equally. The MAb is devoid of several drawbacks inherent to polyclonal antisera, such as epitope heterogeneity or the contamination with irrelevant antibodies raised against other ligands. In this study, we used these two MAbs against ANP to examine the effect of passive immunization in two rat models of hypertension, SHR-SP and DOCA-salt rats, during the course of the development of hypertension, to clarify the possible pathophysiological significance of endogenous ANP in the evolution of hypertension.

\section{Methods}

Preparation and administration of MAb against ANP. The preparation of MAbs against ANP was performed by standard methods as described previously in detail $(25,26)$. In these experiments, we used two MAbs against ANP: one was an MAb directed towards the $\mathrm{NH}_{2}$ terminus of $\alpha$-ANP, a common portion of the amino acid sequence of $\alpha$-rANP and $\alpha$-hANP, which was named KY-ANP-II (MAb[KYANP-II]) (26). The RIA for this antibody MAb[KY-ANP-II] showed equal cross-reactivities with $\alpha$-rANP and $\alpha$-hANP, but $\mathrm{NH}_{2}$-terminally deleted forms of $\alpha$-ANP, that is, $\alpha$-rANP[4-28], $\alpha$-rANP[5-28], $\alpha$ hANP[4-28], and $\alpha$-hANP[5-28] exhibited cross-reactivities of $<0.01 \%$ on a molar basis (Table I). Thus, we used MAb[KY-ANP-II] for the blockade of circulating endogenous ANP in the rat, $\alpha$-rANP $(27,28)$. The other MAb, which we used in this study as a control, is an MAb with weak binding affinity for $\alpha$-rANP that recognized the epitope located in the $\mathrm{NH}_{2}$-terminal half of the ring structure of $\alpha$-hANP including [Met ${ }^{12}$ ] residue and was named KY-ANP-I (MAb[KYANP-I]) (25). The RIA with MAb[KY-ANP-I] demonstrated cross-reactivity of $0.9 \%$ with $\alpha$-rANP on a molar basis, as shown in Table I. The MAb in ascites were available in the RIA for $\alpha$-hANP at final dilutions of $1: 10^{7}$ for MAb[KY-ANP-II] $\left(\mathrm{K}_{a}=6.6 \times 10^{10} \mathrm{M}^{-1}\right.$ for $\alpha$-hANP) and of $1: 10^{3}$ for MAb[KY-ANP-I] $\left(\mathrm{K}_{a}=3.1 \times 10^{10} \mathrm{M}^{-1}\right.$ for $\alpha$-hANP), which bind $\sim 20 \%$ of ${ }^{125} \mathrm{I}-\alpha$-hANP at a concentration of 60-120 pM, comparable to the endogenous circulating ANP level (7, $14,17)$.

In chronic repetitive administrations (experiments 1, 2, and 6), 100 $\mu l$ of ascitic fluid containing either MAb[KY-ANP-II] or MAb[KYANP-I] was intravenously injected as a bolus through the tail vein. In acute experiments (experiments 3, 4, and 5), $100 \mu \mathrm{l}$ of ascitic fluid containing MAb[KY-ANP-II] was diluted with isotonic saline to a total volume of $500 \mu \mathrm{l}$ and injected over $30 \mathrm{~s}$ via a venous silastic catheter as previously reported $(7,29)$.

Table I. Specificity of two MAbs against ANP, MAb[KY-ANP-II $]$ and $M A b[K Y-A N P-I]$

\begin{tabular}{lcc}
\hline \multicolumn{1}{c}{ Peptide } & MAb[KY-ANP-II] & MAb[KY-ANP-I] \\
\hline$\alpha$-hANP & 100 & 100 \\
$\alpha$-rANP(cardionatrin) & 100 & 0.9 \\
$\alpha$-hANP[3-28] & 0.2 & 100 \\
$\alpha$-rANP[3-28] & 0.2 & 0.9 \\
$\alpha$-hANP[4-28] & $<0.01$ & 100 \\
$\alpha$-rANP[4-28](ANF IV, & & \\
$\quad$ auriculin B) & $<0.01$ & 0.9 \\
$\alpha$-hANP[5-28] & $<0.001$ & 100 \\
$\alpha$-rANP[5-28](atriopeptin III) & $<0.001$ & 0.9 \\
$\alpha$-hANP[7-28] & $<0.001$ & 100 \\
$\alpha$-rANP[5-27](atriopeptin II) & $<0.001$ & 0.9 \\
& & \\
\hline
\end{tabular}

Values are cross-reactivities of peptides on a molar basis in the RIA using ${ }^{125} \mathrm{I}-\alpha$-hANP as a tracer and $\alpha$-hANP as a standard (percent).
Measurement of blood pressure and determination of urine volume and urinary electrolyte excretions. Blood pressure was measured periodically by the noninvasive tail cuff method (model USM 105R; Ueda Manufacturing Co., Tokyo, Japan) as previously described (30), and values were determined as the means of 10 consecutive determinations for each rat. Urine was collected over a 2- (experiment 1) or 3-d (experiment 2) observation period after a 1-d acclimation period from each rat in a metabolism cage (model KN-646 [B-2]; Natsume Manufacturing Co., Tokyo, Japan). Urinary concentrations of sodium and potassium were determined by the ion electrode method (Hitachi autoanalyzer model 736; Hitachi Medical Co., Tokyo, Japan).

Determination of plasma ANP levels, cGMP levels, and other biochemical data. Blood $(250 \mu \mathrm{l})$ was obtained through the venous catheter from conscious, unrestrained rats as previously described $(7,14)$. Plasma ANP concentrations in rats were determined by the RIA with a rabbit polyclonal antiserum raised against a $\mathrm{COOH}$-terminal fragment of $\alpha$-ANP, $\alpha$-ANP [17-28], as described previously in details (31). The RIA can equally recognize $\alpha$-ANP[17-28], $\alpha$-rANP, $\alpha$-hANP, $\alpha$ rANP[3-28], $\alpha$-rANP[4-28], and $\alpha$-rANP[5-28]. The lowest detectable concentration of ANP was $1 \mathrm{pg} /$ tube and the amount of $50 \%$ binding inhibition $\left(\mathrm{IC}_{50}\right)$ was $25 \mathrm{pg} /$ tube. Plasma ANP-like immunoreactivity was determined with $25 \mu \mathrm{l}$ of rat plasma without extraction $(7,14,17)$.

Plasma cGMP concentrations were determined with a commercially available RIA kit (YAMASA cyclic GMP assay kit; Yamasa Shoyu Co., Chiba, Japan) according to the method of Steiner et al. (32). Serum sodium, potassium, creatinine, and blood urea nitrogen were determined by the standard analytical techniques.

Experiment 1. Chronic administration of MAb against ANP to SHR-SP and Wistar Kyoto rats (WKY). 16 male SHR-SP (weighing $134 \pm 2 \mathrm{~g}$ ) at the age of $6 \mathrm{wk}$ and 16 age-matched male normotensive WKY (weighing $138 \pm 3 \mathrm{~g}$ ) were used. Rats were maintained in Shionogi Research Laboratories (Shionogi \& Co., Osaka, Japan). Three animals were housed per cage and subjected to $12 \mathrm{~h}$ of light and $12 \mathrm{~h}$ of dark (light on from 7:00 a.m. to 7:00 p.m.) in a temperature-controlled $\left(25 \pm 1^{\circ} \mathrm{C}\right)$ room and fed standard rat chow containing $0.19 \%$ sodium and $0.52 \%$ potassium and tap water ad lib. Rats in both strains were randomly divided into two groups: SHR-SP in group $1 \mathrm{~A}(n=8)$ received weekly intravenous injections of $100 \mu$ lascitic fluid containing MAb[KY-ANP-II]. SHR-SP in group $1 \mathrm{~B}(n=8)$ received weekly intravenous injections of $100 \mu \mathrm{l}$ ascitic fluid containing MAb[KY-ANP-I] as a control. WKY in group $1 \mathrm{C}(n=8)$ received weekly injections of $100 \mu l$ ascitic fluid containing MAb[KY-ANP-II] and WKY in group $1 \mathrm{D}(n=8)$, the same amount of MAb[KY-ANP-I]. Administrations of ascitic fluid were performed four times: just after the measurement of blood pressure and urine volume and urinary excretions of sodium and potassium when rats were $6 \mathrm{wk}$ old, and then, weekly when they were 7,8 and 9 wk old, each time the day before the weekly determination of blood pressure. When rats were $10 \mathrm{wk}$ old, urine volume and urinary excretions of sodium and potassium were again measured.

Experiment 2. Chronic administration of MAb against ANP to DOCA-salt rats. 30 male Slc:Wistar rats (Shizuoka Animal Center, Shizuoka, Japan, weighing $315 \pm 3 \mathrm{~g}$ ) kept under the conditions described in experiment 1 were offered $1 \% \mathrm{NaCl}$ solution as drinking fluid. DOCA (Sigma Chemical Co., St. Louis, MO) dissolved in corn oil (Sigma Chemical Co.) was intramuscularly injected at weekly intervals at a dosage of $20 \mathrm{mg}(0.2 \mathrm{ml})$ (DOCA-salt rats, groups $2 \mathrm{~A}$ and 2B). Another groups of rats $(n=8$, weighing $318 \pm 3 \mathrm{~g})$ were given tap water to drink and injected weekly with $0.2 \mathrm{ml}$ of corn oil, the vehicle only (control rats, group 2C). DOCA-salt rats were randomly divided into two groups: DOCA-salt rats in group $2 \mathrm{~A}(n=15)$ received weekly intravenous injections of $100 \mu \mathrm{l}$ ascitic fluid containing MAb[KYANP-II] and those in group $2 \mathrm{~B}(n=15)$ received the same amount of ascites containing MAb[KY-ANP-I]. Administrations of ascitic fluid were performed nine times: just after the determination of blood pressure before DOCA and $1 \% \mathrm{NaCl}$ administration, and then, weekly for the next $8 \mathrm{wk}$. The blood pressure of the rats in the three groups was measured at 2-wk intervals, each time the day after the administration 
of ascites containing MAbs. 8 wk after the start of the treatment, urine volume and urinary excretions of sodium and potassium were determined in three groups of rats, using the metabolism cage by offering rats in all three groups $1 \% \mathrm{NaCl}$ to drink. After that, blood sampling was performed while rats were in a conscious, unrestrained state through a venous catheter as described above.

Experiment 3. Time course of titer change of administered $M A b[K Y-A N P-I I]$ in rats in vivo. 12 male Slc: Wistar rats (Shizuoka Animal Center) weighing 200-300 g were intravenously injected with $100 \mu \mathrm{l}$ ascitic fluid containing MAb[KY-ANP-II] through a venous catheter as described above. Blood was collected through a venous catheter $1 \mathrm{~d}$ after $(0 \mathrm{wk})$ and 1,2 and $3 \mathrm{wk}$ after the administration of ascites from three rats each time. Serum obtained in this way and serum obtained from DOCA-salt rats in group 2A, diluted to a final dilution of 1:500, were incubated with ${ }^{125} \mathrm{I}-\alpha$-hANP (the specific activity: $400-800 \mu \mathrm{Ci} / \mu \mathrm{gg}, \sim 9,900 \mathrm{cpm})(31)$ at $4^{\circ} \mathrm{C}$ for $20 \mathrm{~h}$ and the specific binding of ${ }^{125} \mathrm{I}-\alpha$-hANP (the gross binding of ${ }^{125} \mathrm{I}-\alpha$-hANP minus the nonspecific binding of ${ }^{125} \mathrm{I}-\alpha$-hANP with diluted pooled normal rat serum) was determined.

Experiment 4. Effect of $M A b[K Y-A N P-I I]$ to antagonize plasma cGMP response to exogenous and endogenous $A N P$ in rats in vivo. Experiment 4-1: Male Slc: Wistar rats $(200-300 \mathrm{~g})$ in group 4-1A ( $n$ $=4)$ received an intravenous bolus injection of synthetic $\alpha$-hANP (Protein Research Foundation, Osaka, Japan) at a dose of $5 \mu \mathrm{g}$. Rats in group 4-1B $(n=4)$ were pretreated with $100 \mu \mathrm{l}$ ascitic fluid containing MAb[KY-ANP-II] 5 min before the administration of $5 \mu \mathrm{g}$ of $\alpha$-hANP. Blood was collected before and 5, 10, and $20 \mathrm{~min}$ after the administration of $\alpha$-hANP through a venous catheter.

Experiment 4-2: Male Slc: Wistar rats $(200-300 \mathrm{~g})$ in group 4-2A ( $n$ $=4$ ) received an intravenous bolus injection of synthetic arginine-vasopressin (AVP) (Protein Research Foundation, Osaka, Japan) at a dose of $5 \mu \mathrm{g}$. Rats in group 4-2B $(n=4)$ were pretreated with $100 \mu \mathrm{l}$ ascitic fluid containing MAb[KY-ANP-II] $5 \mathrm{~min}$ before the administration of $5 \mu \mathrm{g}$ of AVP. Blood was collected before and 2, 5, 10, and 20 min after the administration of AVP.

Plasma cGMP levels in the four groups (4-1 A and B; 4-2 A and B) and plasma ANP levels in groups 4-1A and 4-2A were determined as described above.

Experiment 5. Determination of basal plasma ANP and cGMP levels in SHR-SP and WKY and acute effect of intravenously administered MAb[KY-ANP-II] on plasma GMP level. Nine 9-wk-old male SHR-SP and nine male age-matched WKY from the same source in experiment 1 were prepared for the venous sampling as described above. Blood was obtained from each rat for the determination of basal plasma ANP and cGMP levels in conscious unrestrained state. Among them, eight rats, four of SHR-SP and four of WKY, further received an intravenous administration of $100 \mu \mathrm{l}$ ascites containing MAb[KYANP-II] and blood was collected $5 \mathrm{~min}$ before ( $-5 \mathrm{~min})$, just before ( 0 min) and 5, 10, 15, and 20 min after the administration of MAb[KYANP-II]. The plasma cGMP level for each sampling point was determined.

Experiment 6. Comparison of progression of hypertension between untreated SHR-SP and DOCA-salt rats and those treated with ANP $M A b$. To further validate the effect of MAb against ANP on blood pressure, the progression of hypertension between untreated SHR-SP and DOCA-salt rats and those treated with ANP MAb was compared.

In experiment 6-1, 21 38-d-old male SHR-SP $(105 \pm 2 \mathrm{~g})$ from the same source in experiment 1 were randomly divided into three groups. SHR-SP in group 6-1A received weekly intravenous injections of 100 $\mu \mathrm{l}$ ascitic fluid containing MAb[KY-ANP-II] and SHR-SP in group 6-1B received the same amount of control MAb[KY-ANP-I], as described in experiment 1. SHR-SP in group 6-1C did not receive any injection of MAb-containing ascites and served to be another control animals. Blood pressure of each SHR-SP was determined weekly, as described in experiment 1.

In experiment 6-2, 17 male Slc: Wistar rats $(320 \pm 2 \mathrm{~g})$ from the same source in experiment 2 received the same treatment of DOCA and $1 \% \mathrm{NaCl}$ administration, and were divided into two groups. DOCA-salt rats in group 6-2A $(n=9)$ received weekly intravenous injections of $100 \mu \mathrm{l}$ ascitic fluid containing control MAb[KY-ANP-I], whereas those in group 6-2B $(n=8)$ did not receive any injection of MAb-containing ascites. Blood pressure of each DOCA-salt rat was measured at intervals of $2 \mathrm{wk}$, as described in experiment 2 until $6 \mathrm{wk}$ after the start of the treatment.

Statistical analysis. All values are expressed as mean \pm SEM. Analysis of variance of repeated measures, with subsequent Duncan's test, was used to determine significant changes during time-dependent multiple observations (33). Linear regression analysis was performed with the method of least squares. The statistical significance was defined as $P<0.05$.

\section{Results}

Experiment 1. Fig. 1 shows changes of blood pressure of SHRSP and WKY treated with two different MAb against ANP.
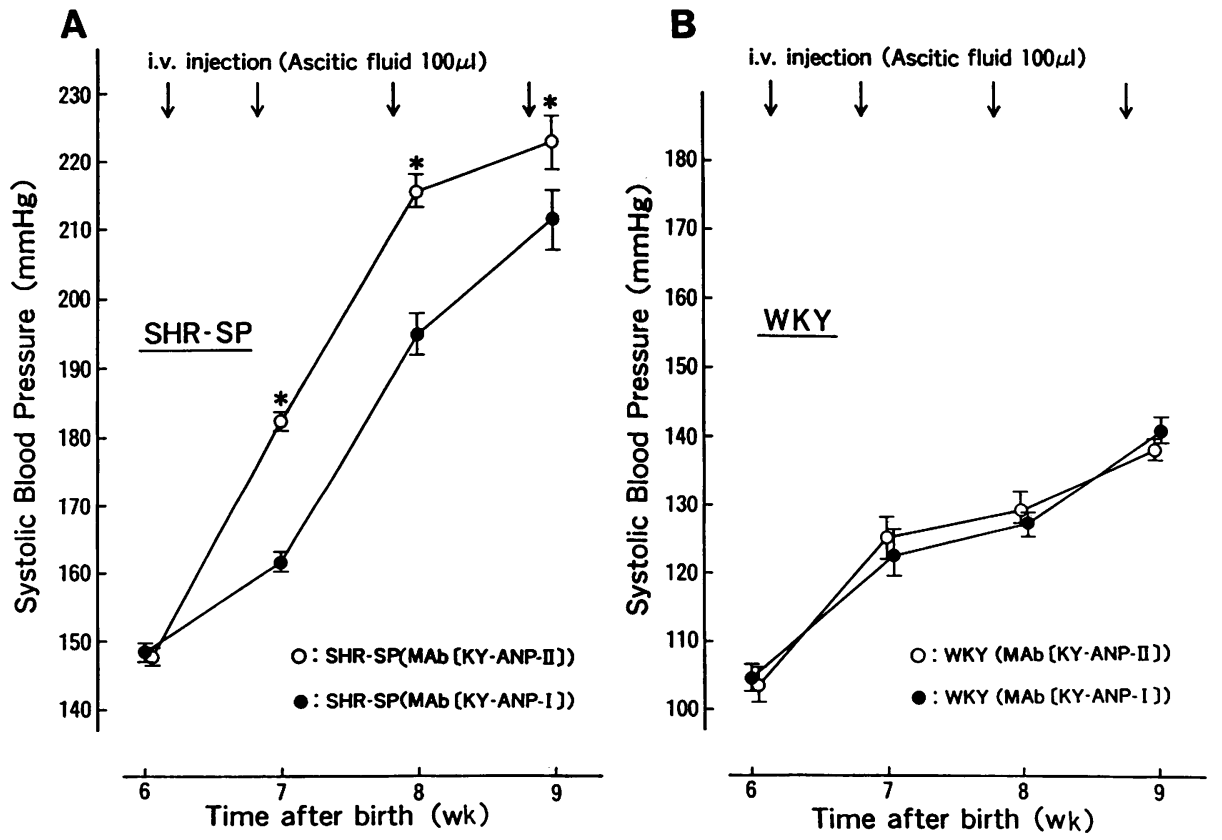

Figure 1. Effect of chronic repetitive administrations of MAb against ANP on blood pressure of $(A)$ SHR-SP and (B) WKY. (Left) Open circles represent SHR-SP treated with MAb[KY-ANPII] (group 1A) and closed circles represent SHR-SP treated with MAb[KYANP-I] (group 1B). (Right) Open circles are WKY treated with MAb[KY-ANPII] (group 1C) and closed circles are WKY treated with MAb[KY-ANP-I] (group 1D). Significantly different from group 1B. ${ }^{*} P<0.01$. 
Table II. Effect of Chronic Administration of MAb against ANP on Urine Volume, Urinary Excretions of Sodium, and Potassium in SHR-SP and WKY

\begin{tabular}{|c|c|c|c|c|c|c|c|}
\hline \multirow[b]{2}{*}{ Rat group } & \multirow[b]{2}{*}{ Treatment } & \multicolumn{2}{|c|}{ Urine volume } & \multicolumn{2}{|c|}{ Sodium excretion } & \multicolumn{2}{|c|}{ Potassium excretion } \\
\hline & & Before & After & Before & After & Before & After \\
\hline & & \multicolumn{2}{|c|}{$m l / d$} & \multicolumn{4}{|c|}{ mmol/d } \\
\hline Group 1A SHR-SP & MAb[KY-ANP-II] & $7.3 \pm 0.5$ & $11.5 \pm 1.2$ & $0.71 \pm 0.04$ & $0.86 \pm 0.06$ & $1.12 \pm 0.04$ & $1.67 \pm 0.07$ \\
\hline Group 1B SHR-SP & MAb[KY-ANP-I] & $6.2 \pm 0.3$ & $13.8 \pm 0.7$ & $0.62 \pm 0.03$ & $0.84 \pm 0.04$ & $0.99 \pm 0.07$ & $1.64 \pm 0.07$ \\
\hline Group 1C WKY & MAb[KY-ANP-II] & $6.7 \pm 0.3$ & $11.3 \pm 1.1$ & $0.77 \pm 0.10$ & $0.67 \pm 0.07$ & $1.20 \pm 0.13$ & $1.17 \pm 0.23$ \\
\hline Group 1D WKY & MAb[KY-ANP-I] & $7.0 \pm 0.4$ & $12.6 \pm 2.0$ & $0.66 \pm 0.03$ & $0.82 \pm 0.13$ & $1.43 \pm 0.11$ & $1.51 \pm 0.34$ \\
\hline
\end{tabular}

Values are means \pm SEM of the 3-d observation period. Before, before treatment, when rats were 6 wk old. After, after treatment, when rats were 10 wk old.

Before the repetitive administrations of $\mathrm{MAb}$, blood pressure of SHR-SP in groups $1 \mathrm{~A}$ and $1 \mathrm{~B}(n=16,148 \pm 1 \mathrm{mmHg})$ was significantly higher than that of WKY in groups $1 \mathrm{C}$ and $1 \mathrm{D}(n$ $=16,104 \pm 2 \mathrm{mmHg})(P<0.01)$ and this difference was maintained throughout the observation period, with the time-dependent, significant increase of blood pressure of both rat strains.

1 wk after the start of the administration of MAb-containing ascites (two injections), SHR-SP in group 1A, which received MAb[KY-ANP-II] with high affinity for $\alpha$-rANP, exhibited significantly higher blood pressure $(182 \pm 2 \mathrm{mmHg})$ than that of SHR-SP in group $1 \mathrm{~B}(162 \pm 2 \mathrm{mmHg}, P<0.01)$, which received MAb[KY-ANP-I] with low affinity for $\alpha$ rANP, though blood pressure before the treatment was not significantly different in the two groups $(148 \pm 2 \mathrm{mmHg}$ for group $1 \mathrm{~A}$ and $148 \pm 1 \mathrm{mmHg}$ for group $1 \mathrm{~B}$ ). The trend of significantly higher blood pressure of SHR-SP in group 1A compared with group $1 \mathrm{~B}$ persisted throughout the observation period of the following $2 \mathrm{wk}$. In contrast to SHR-SP, there was no appreciable difference in blood pressure throughout the obser- vation period between WKY treated with MAb[KY-ANP-II] (group 1C) and with MAb[KY-ANP-I] (group 1D).

Effects of the chronic administration of two MAbs against ANP on urine volume and urinary electrolyte excretions are shown in Table II. No significant differences in any renal excretory parameters were observed between the two rat strains or the two treatments.

Experiment 2. Fig. 2 illustrates the evolution of hypertension in DOCA-salt rats treated with two different MAb against ANP and control rats without the administration of MAbs. Blood pressure of the rats in three groups did not significantly differ before the treatment $(139 \pm 7 \mathrm{mmHg}$ in group $2 \mathrm{~A}, 133 \pm 6$ $\mathrm{mmHg}$ in group $2 \mathrm{~B}$, and $139 \pm 3 \mathrm{mmHg}$ in group $2 \mathrm{C}$ ). In the rats in group $2 \mathrm{C}$, which received weekly vehicle corn oil injections and were offered tap water to drink, blood pressure did not significantly alter throughout the observation period. DOCA and $1 \% \mathrm{NaCl}$ administration caused a significant and progressive rise in blood pressure of the rats in both groups $2 \mathrm{~A}$ and 2B. Blood pressure of DOCA-salt rats in group 2A (173 \pm 5 $\mathrm{mmHg}$ ) was significantly higher than that of untreated control

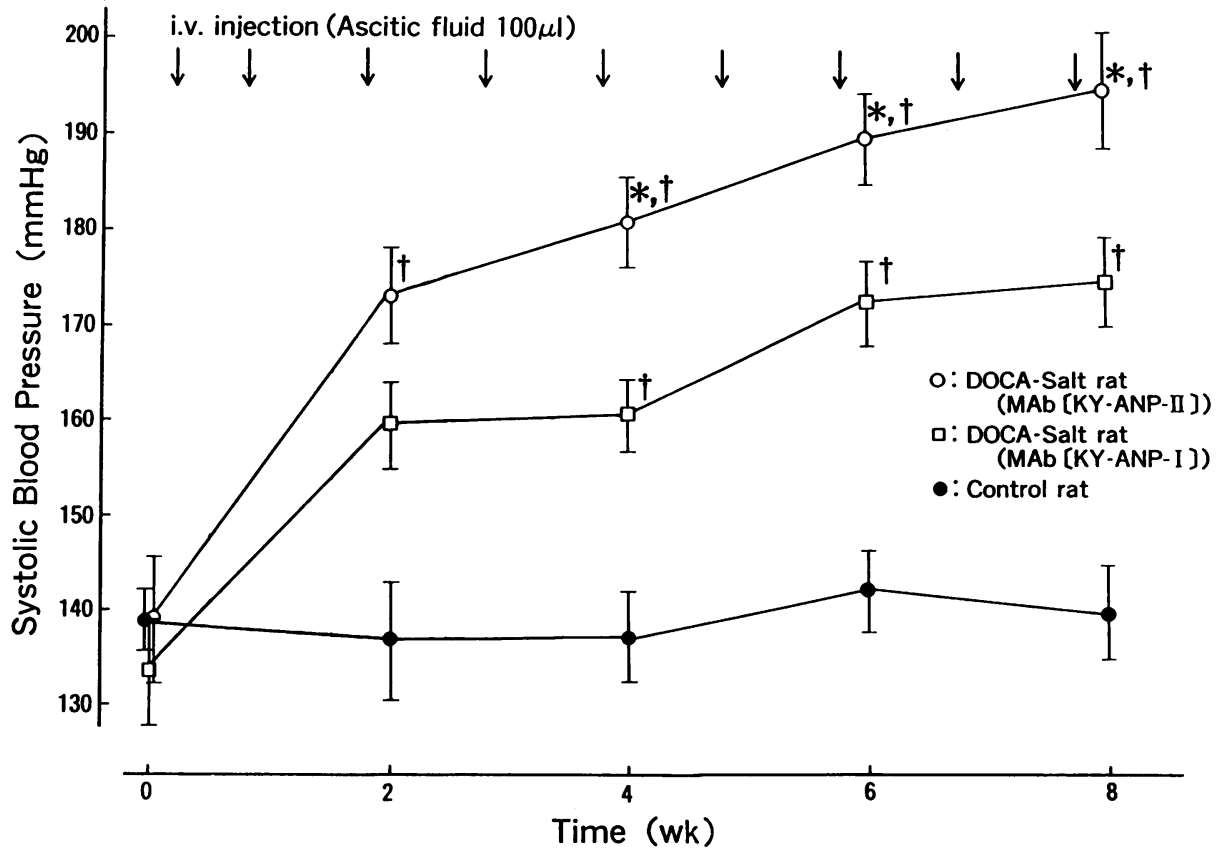

Figure 2. Effect of chronic repetitive administrations of monoclonal antibodies against ANP on blood pressure of DOCA-salt rats. Open circles represent DOCA-salt rats treated with MAb[KY-ANP-II] (group 2A) and open squares represent DOCA-salt rats treated with MAb[KY-ANP-I] (group 2B). Closed circles are control rats without treatment (group 2C). Significantly different from group $2 \mathrm{~B}$. ${ }^{*} P$ $<0.05$, significantly different from group $2 \mathrm{C} . \dagger P<0.01$. 
Table III. Effect of Chronic Administration of MAbs against ANP on Urine Volume, Urinary Excretions of Sodium and Potassium, and Serum Levels of Sodium, Potassium, Creatinine, and Blood Urea Nitrogen in DOCA-Salt Rats

\begin{tabular}{lcccccccc}
\hline \multicolumn{1}{c}{ Rat group (treatment) } & $\begin{array}{c}\text { Body } \\
\text { weight }\end{array}$ & $\begin{array}{c}\text { Urine } \\
\text { volume }\end{array}$ & $\begin{array}{c}\text { Sodium } \\
\text { excretion }\end{array}$ & $\begin{array}{c}\text { Potassium } \\
\text { excretion }\end{array}$ & $\begin{array}{c}\text { Serum } \\
\text { sodium }\end{array}$ & $\begin{array}{c}\text { Serum } \\
\text { potassium }\end{array}$ & $\begin{array}{c}\text { Serum } \\
\text { creatinine }\end{array}$ & $\begin{array}{c}\text { Blood urea } \\
\text { nitrogen }\end{array}$ \\
\hline & $g$ & $m l / d$ & mmol/d & mmollliter & $\mu m o l / l i t e r$ & $m m o l / l i t e r$ \\
Group 2A DOCA-salt rats (MAb[KY-ANP-II]) & $489 \pm 25$ & $69 \pm 11^{* \ddagger}$ & $12.0 \pm 2.0^{* \ddagger}$ & $2.1 \pm 0.2$ & $140.1 \pm 0.4^{\ddagger}$ & $4.8 \pm 0.2^{\ddagger}$ & $53 \pm 3^{\ddagger}$ & $5.7 \pm 0.2^{\ddagger}$ \\
Group 2B DOCA-salt rats (MAb[KY-ANP-I]) & $495 \pm 12$ & $106 \pm 12^{\S}$ & $18.6 \pm 2.1^{\S}$ & $2.7 \pm 0.2$ & $142.7 \pm 1.1^{\S}$ & $4.8 \pm 0.2^{\ddagger}$ & $53 \pm 3^{\ddagger}$ & $5.9 \pm 0.2$ \\
Group 2C control rats (none) & $514 \pm 32$ & $20 \pm 2$ & $5.0 \pm 0.8$ & $2.4 \pm 0.3$ & $137.0 \pm 1.1$ & $5.5 \pm 0.2$ & $65 \pm 3$ & $6.5 \pm 0.3$ \\
& & & & & & & &
\end{tabular}

Urinary values are means \pm SEM of the $2-\mathrm{d}$ observation period $8 \mathrm{wk}$ after the start of treatment. Blood samples were obtained after the 2-d observation period. ${ }^{*} P<0.05$, significantly different from group $2 \mathrm{~B}$. ${ }^{\ddagger} P<0.05,{ }^{\S} P<0.01$, significantly different from group $2 \mathrm{C}$.

rats in group $2 \mathrm{C}(137 \pm 6 \mathrm{mmHg})$ as early as $2 \mathrm{wk}$ after the start of the treatment $(P<0.01)$, and blood pressure of DOCA-salt rats in group $2 \mathrm{~B}$ became significantly higher $4 \mathrm{wk}$ after the start of the treatment $(160 \pm 4 \mathrm{mmHg})$ than that of control rats $(136 \pm 5 \mathrm{mmHg}, P<0.01$ ).

As with the case in the development of hypertension in SHR-SP, the chronic repetitive administrations of the MAb against $\alpha$-rANP accelerated the progression of blood pressure elevation in DOCA-salt rats. Blood pressure of DOCA-salt rats in group $2 \mathrm{~A}$ treated with MAb[KY-ANP-II] 4 wk after the start of the administration $(180 \pm 5 \mathrm{mmHg})$ was significantly higher than that in group 2B treated with MAb[KY-ANP-I] $(160 \pm 4 \mathrm{mmHg}, P<0.05)$ and the significant difference persisted for the next $4 \mathrm{wk}$.

Table III summarizes effects of the chronic administration of two MAbs against ANP on urine volume and urinary electrolyte excretions of DOCA-salt rats after the completion of nine administrations of MAbs. DOCA-salt rats in group 2B excreted five times volume of urine $(P<0.01)$ and 3.7 times more sodium $(P<0.01)$ than those of control rats in group $2 \mathrm{C}$, although potassium excretions were comparable in these two groups. The chronic repetitive administrations of MAb[KYANP-II] attenuated diuresis and natriuresis induced by DOCA and $1 \% \mathrm{NaCl}$ administration. Urine volume and urinary excretion of sodium of DOCA-salt rats treated with MAb[KYANP-II] in group $2 \mathrm{~A}$ were significantly lower than those of DOCA-salt rats in group 2B $(P<0.05$, respectively). As shown in Table III, however, there was no significant difference in serum sodium, potassium, creatinine or blood urea nitrogen level between group 2A and group 2B. Serum sodium levels in DOCA-salt rats both in groups $2 \mathrm{~A}$ and $2 \mathrm{~B}$ were significantly higher than that in control rats in group $2 \mathrm{C}$, and conversely,

Table IV. Effect of Chronic Administration of MAbs against ANP on Plasma cGMP level in DOCA-Salt Rats

\begin{tabular}{llc}
\hline \multicolumn{1}{c}{ Rat group } & \multicolumn{1}{c}{ Treatment } & Plasma cGMP \\
\hline & & $p m o l / m l$ \\
Group 2A DOCA-salt & MAb[KY-ANP-II] & $4.0 \pm 2.2^{*}$ \\
Group 2B DOCA-salt & MAb[KY-ANP-I] & $12.0 \pm 2.2^{\ddagger}$ \\
Group 2C control & None & $2.9 \pm 1.0$
\end{tabular}

Values are means \pm SEM.

Plasma samples were obtained $\mathbf{8}$ wk after the start of treatment.

* $P<0.05$, significantly different from group $2 \mathrm{~B}$.

${ }^{\ddagger} P<0.01$, significantly different from group $2 \mathrm{C}$. serum potassium levels in DOCA-salt rats both in groups $2 \mathrm{~A}$ and $2 \mathrm{~B}$ were significantly lower than that in control rats in group $2 \mathrm{C}$.

Plasma cyclic GMP levels of the rats in three groups after the completion of nine administrations of MAb against ANP are shown in Table IV. The plasma cyclic GMP level of DOCA-salt rats in group 2B was significantly elevated compared with that of untreated control rats in group $2 \mathrm{C}$. The plasma cyclic GMP level of DOCA-salt rats in group 2A treated with MAb[KY-ANP-II] was significantly lower than that of DOCA-salt rats in group $2 \mathrm{~B}(P<0.05)$ and was suppressed to the level of control rats in group $2 \mathrm{C}$.

Experiment 3. The in vivo diminution of titer of MAb[KY-ANP-II] administered intravenously into rats is demonstrated in Fig. 3. The binding of ${ }^{125} \mathrm{I}-\alpha$-hANP with serum obtained $1 \mathrm{~d}$ after the administration of $\mathrm{MAb}[\mathrm{KY}$ ANP-II]-containing ascites (0 week), at a final dilution of 1:500, was compatible with our results of the binding of ${ }^{125} \mathrm{I}-\alpha$-hANP with MAb[KY-ANP-II] in vitro described previously (26), assuming that a rat plasma volume is $10 \mathrm{ml}(34)$. As shown in Fig. 3, the binding ability of administered MAb[KY-ANP-II] to $\alpha$-ANP was well retained for the following 2 wk.

In the same series of the radiobinding assay, the specific binding of ${ }^{125} \mathrm{I}-\alpha$-hANP with serum at the same dilution obtained from DOCA-salt rats in group 2A, 1 wk after the last administration of MAb[KY-ANP-II], was $3,400 \pm 20 \mathrm{cpm}$. This value was comparable to the specific binding of ${ }^{125} \mathrm{I}-\alpha$ hANP $(3,950 \pm 25 \mathrm{cpm})$ with serum obtained from Slc: Wistar

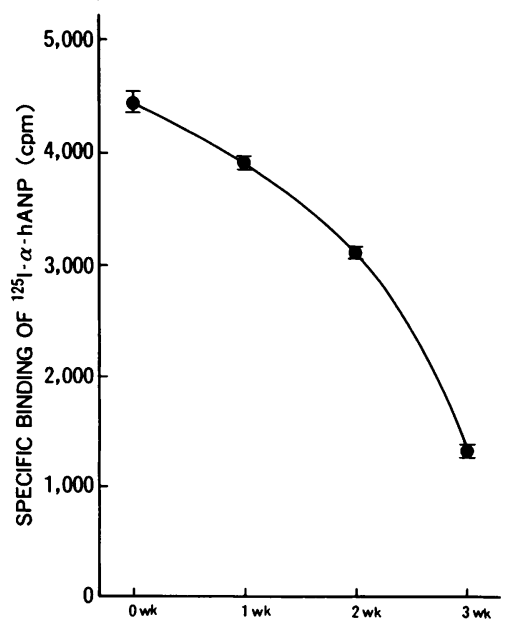

Figure 3. Time course of titer change of MAb[KY-ANP-II] administered intravenously into rats in vivo. Each closed circle represents the specific binding of ${ }^{125} \mathrm{I}-\alpha$-hANP $(9,900 \mathrm{cpm})$ incubated with diluted serum obtained weekly after the administration of 100 $\mu 1$ MAb[KY-ANP-II] from three rats for each time, for $20 \mathrm{~h}$ at $4^{\circ} \mathrm{C}$. 
rats, 1 wk after the administration of MAb[KY-ANP-II] in experiment 3 shown in Fig. 3.

Experiment 4. A bolus injection of $5 \mu \mathrm{g}$ of synthetic $\alpha$ hANP produced a prompt and significant increase of the plasma cGMP level in rats in group 4-1A (Fig. $4 A$ ). The plasma ANP level rose up to $2,240 \pm 280 \mathrm{pg} / \mathrm{ml} 5 \mathrm{~min}$ after the administration, and administered $\alpha$-hANP rapidly disappeared from the rat circulation (Fig. $4 C$ ). There was a significant positive correlation between plasma ANP levels and plasma cyclic GMP levels $(r=0.91, P<0.01)$.

The pretreatment with $100 \mu \mathrm{l}$ ascitic fluid containing MAb[KY-ANP-II] significantly attenuated $\alpha$-hANP-induced increase of the plasma cGMP level, as depicted in Fig. $4 \mathrm{~A}$. The plasma cyclic GMP level of rats in group 4-1B 5 min after the administration of $\alpha$-hANP $(37 \pm 6 \mathrm{pmol} / \mathrm{ml})$ was significantly lower than the corresponding value in group 4-1A (77 \pm 12 $\mathrm{pmol} / \mathrm{ml}, P<0.01)$.
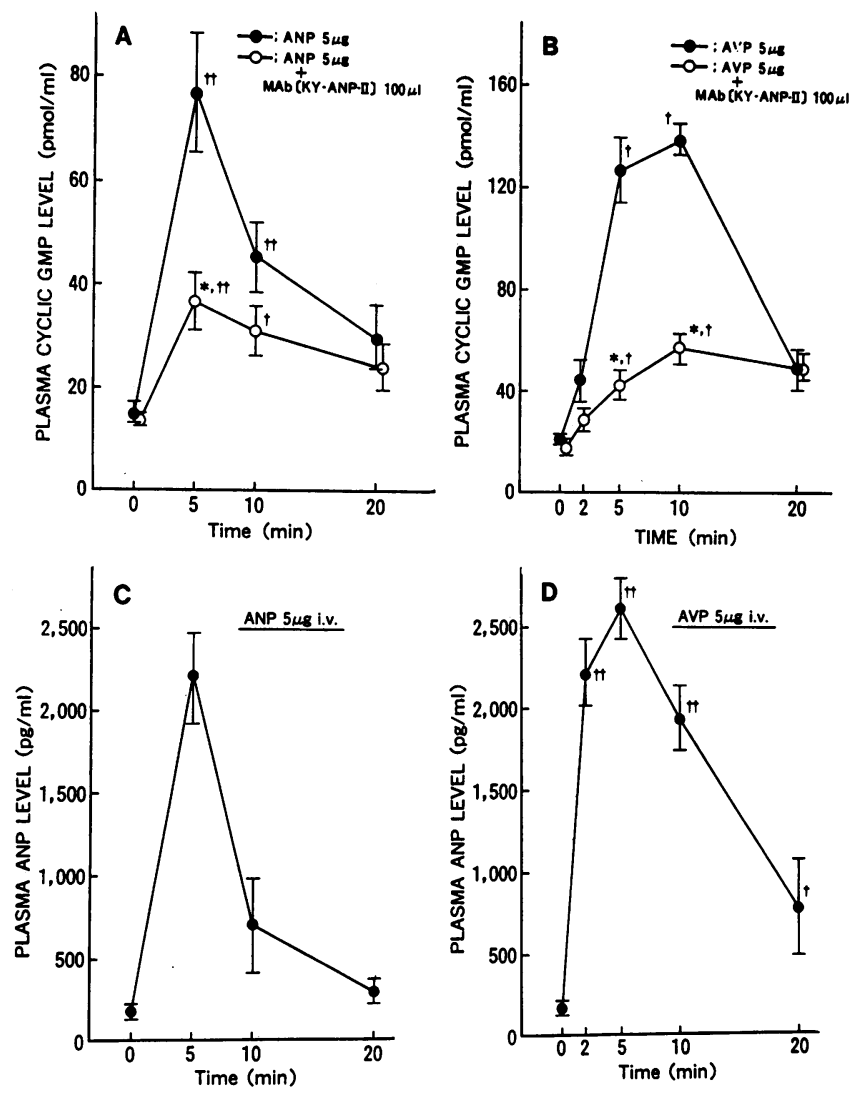

Figure 4. Effect of the intravenous administration of MAb[KY-ANPII] on plasma cGMP elevation induced by exogenous and endogenous ANP. $A$, closed circles represent plasma CGMP levels of rats in group 4-1A that received $5 \mu \mathrm{g} \alpha$-hANP administration and open circles represent those of rats in group 4-1B that were pretreated with $100 \mu$ l of MAb[KY-ANP-II] followed by $5 \mu \mathrm{g} \alpha$-hANP administration. Significantly different from group 4-1A. ${ }^{*} P<0.01$. Significantly different from the basal level $(0 \mathrm{~min}) . \dagger P<0.05, \dagger \dagger P<0.01$. $C$ shows the plasma ANP level in group 4-1A. In $B$, closed circles represent plasma cGMP levels of rats in group 4-2A that received 5 $\mu \mathrm{g}$ AVP administration and open circles represent those of rats in group 4-2B that were pretreated with $100 \mu \mathrm{l}$ of MAb[KY-ANP-II] followed by $5 \mu \mathrm{g}$ AVP administration. Significantly different from group 4-2A. ${ }^{*} P<0.01$. Significantly different from the basal level $(0$ $\min ) . \dagger P<0.01$. $D$ shows the plasma ANP level in group 4-2A. Significantly different from the basal level. $\uparrow P<0.05,+\dagger P<0.01$.
The intravenous bolus injection of $5 \mu \mathrm{g}$ AVP caused a massive rise in the plasma ANP level, which persisted until 20 min after the administration, as previously reported $(7,35)$ (Fig. $4 \mathrm{D}$ ). After the administration of $5 \mu \mathrm{g} \mathrm{AVP,} \mathrm{a} \mathrm{parallel} \mathrm{rise}$ of the plasma cyclic GMP level was observed in rats in group 4-2A, as shown in Fig. $4 \mathrm{~B}$. There was a significant positive correlation between plasma ANP levels and plasma cGMP levels after the AVP administration $(r=0.70, P<0.01)$.

The pretreatment with $100 \mu \mathrm{l}$ ascitic fluid containing MAb[KY-ANP-II] significantly suppressed the increase of the plasma cGMP level associated with the AVP-induced elevation of endogenous ANP level (Fig. 4B). The plasma cGMP levels in rats in group 4-2B $5 \mathrm{~min}(44 \pm 6 \mathrm{pmol} / \mathrm{ml})$ and $10 \mathrm{~min}$ $(58 \pm 6 \mathrm{pmol} / \mathrm{ml})$ after the AVP administration were significantly lower than those in rats in group 4-2A (128 $\pm 13 \mathrm{pmol} /$ $\mathrm{ml}, P<0.01 ; 140 \pm 8 \mathrm{pmol} / \mathrm{ml}, P<0.01$, respectively).

Experiment 5. The mean basal plasma ANP level of SHRSP at the age of 9 wk was $303 \pm 51 \mathrm{pg} / \mathrm{ml}(n=9)$, which was significantly higher than that of age-matched WKY, 143 \pm 21 $\mathrm{pg} / \mathrm{ml}(n=9)(P<0.05)$. The simultaneously determined plasma cGMP levels were $11.3 \pm 0.7 \mathrm{pmol} / \mathrm{ml}$ for SHR-SP and $7.5 \pm 0.4 \mathrm{pmol} / \mathrm{ml}$ for WKY. The difference of plasma cyclic GMP levels in the two rat strains was significant $(P<0.01)$, and there was a significant positive correlation between plasma ANP levels and plasma cyclic GMP levels $(r=0.70, P<0.01)$.

Fig. 5 illustrates the effect of the intravenous administration of MAb[KY-ANP-II] on basal plasma cyclic GMP levels of SHR-SP and WKY. The basal plasma cGMP levels of SHR-SP $(n=4) 5 \mathrm{~min}$ before and just before the administration of the MAb-containing ascites (13.7 \pm 1.0 and $12.0 \pm 1.3$ $\mathrm{pmol} / \mathrm{ml})$ were significantly higher than those of WKY $(n=4)$ (7.6 $\pm 0.5 \mathrm{pmol} / \mathrm{ml}, P<0.01 ; 7.6 \pm 0.8 \mathrm{pmol} / \mathrm{ml}, P<0.05$, respectively). The administration of MAb[KY-ANP-II] caused a significant reduction in the plasma cGMP level of SHR-SP compared with the means of their basal levels $(-5 \mathrm{~min}$ and 0 min). After the administration of MAb[KY-ANP-II], the plasma cGMP level of SHR-SP decreased to the level almost same as that of WKY. In contrast to SHR-SP, the administration of MAb[KY-ANP-II] had no appreciable effect on the plasma cGMP level of WKY.

Experiment 6. Table $\mathrm{V}$ shows the comparison of blood pressure of untreated SHR-SP (group 6-1C) and SHR-SP treated with either MAb[KY-ANP-II] (group 6-1A) or

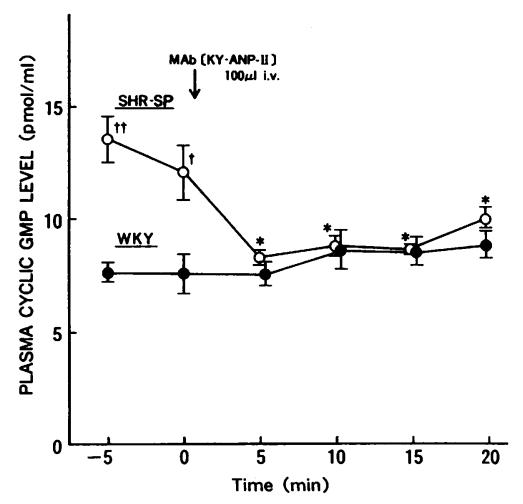

Figure 5. Effect of the intravenous administration of MAb[KY-ANPII] on plasma CGMP levels of SHR-SP and WKY. Open circles represent plasma cGMP levels of SHR-SP ( $n$ $=4)$ and closed circles represent those of WKY $(n=4)$. Significantly different from the basal level (the mean of values of -5 and 0 min). ${ }^{*} P<0.01$. Significantly different from WKY. $\dagger P<0.05$, $+\dagger P<0.01$. 
Table V. Comparison of Progression of Hypertension in Untreated SHR-SP and that in SHR-SP Treated with Chronic Administration of MAbs against ANP

\begin{tabular}{|c|c|c|c|c|}
\hline \multirow[b]{2}{*}{ Rat group (treatment) } & \multicolumn{4}{|c|}{ Systolic blood pressure } \\
\hline & $\begin{array}{c}\text { Before } \\
\text { treatment* }\end{array}$ & 1 wk & $2 \mathrm{wk}$ & $\begin{array}{l}3 \text { wk after the } \\
\text { start of } \\
\text { treatment }\end{array}$ \\
\hline & \multicolumn{4}{|c|}{$m m H g$} \\
\hline \multicolumn{5}{|l|}{ Group 6-1A SHR-SP } \\
\hline (MAb[KY-ANP-II]) & $142 \pm 1$ & $174 \pm 3^{\ddagger \S}$ & $205 \pm 3^{\ddagger \S}$ & $236 \pm 1^{\ddagger \S}$ \\
\hline \multicolumn{5}{|l|}{ Group 6-1B SHR-SP } \\
\hline (MAb[KY-ANP-I]) & $140 \pm 3$ & $152 \pm 3$ & $176 \pm 1$ & $205 \pm 1$ \\
\hline \multicolumn{5}{|l|}{ Group 6-1C SHR-SP } \\
\hline (none) & $142 \pm 1$ & $148 \pm 1$ & $175 \pm 2$ & $207 \pm 3$ \\
\hline
\end{tabular}

Values are means \pm SEM.

* Rats were $38 \mathrm{~d}$ old at the beginning of the experiment.

${ }^{\ddagger} P<0.01$, significantly different from group 6-1B.

${ }^{8} P<0.01$, significantly different from group $6-1 \mathrm{C}$.

MAb[KY-ANP-I] (group 6-1B). As shown in Table V clearly, there was no significant difference in the development of hypertension in SHR-SP without any treatment and SHR-SP which received weekly injections of control MAb[KY-ANP-I]. Blood pressure of SHR-SP treated with MAb[KY-ANP-II] was significantly higher than not only that of SHR-SP treated with MAb[KY-ANP-I] as in experiment 1, but also that of untreated SHR-SP throughout the observation period.

Blood pressure of DOCA-salt rats in group 6-2A treated with MAb[KY-ANP-I] was $139 \pm 1 \mathrm{mmHg}$ (before treatment), $152 \pm 2 \mathrm{mmHg}(2 \mathrm{wk}) 156 \pm 10 \mathrm{mmHg}(4 \mathrm{wk})$ and $167 \pm 6$ $\mathrm{mmHg}$ (6 wk after the start of the treatment). Blood pressure of DOCA-salt rats in group 6-2B without any treatment was $139 \pm 3 \mathrm{mmHg}$ (before treatment), $150 \pm 9 \mathrm{mmHg}$ (2 wk), $158 \pm 4 \mathrm{mmHg}$ ( $4 \mathrm{wk})$ and $170 \pm 5 \mathrm{mmHg}$ ( $6 \mathrm{wk}$ after the start of the treatment). There was, therefore, no significant difference in the evolution of hypertension between DOCA-salt rats without any injection of ANP MAb and those treated with MAb[KY-ANP-I].

\section{Discussion}

To explain the pathophysiological role of augmented secretion of ANP in hypertension, we studied the effects of chronic repetitive administrations of MAbs against ANP in two animal models of hypertension: SHR-SP and DOCA-salt rats. This study clearly demonstrates the acceleration of the development of hypertension by the specific blockade of increased circulating ANP in both hypertensive rats.

The ability of our MAb against $\alpha$-rANP (MAb[KY-ANPII]) to block the biological activities of circulating $\alpha$-rANP was verified in experiment 4 . The pretreatment of MAb[KYANP-II] significantly suppressed the increase of plasma cGMP levels associated with the increase of plasma ANP levels by the administration of exogenous $\alpha$-hANP (experiment 4-1) or by the administration of synthetic AVP (experiment 4-2), which stimulated endogenous ANP secretion from the heart, as previously reported $(7,35)$. The intravenous administration of MAb[KY-ANP-I] with low affinity for $\alpha$-rANP, which we used as a control in this study, elicited no effect on the increase of the plasma cGMP level after the administration of AVP (data not shown).

Several lines of evidence support the concept that ANP activates particulate guanylate cyclase and increases cyclic GMP accumulation in numerous cell types and tissues, including vascular smooth muscle, endothelial cells, fibroblasts, and renal cells (36). In humans and rats, the intravenous administration of ANP was reported to elevate the plasma cGMP level (37). In this study, after the administrations of synthetic $\alpha$-hANP and AVP, there existed significant positive correlations between plasma ANP levels and plasma cGMP levels. In experiment 5, we further observed a significant positive correlation between basal plasma ANP levels and plasma cyclic GMP levels in SHR-SP and WKY. It was also reported that various ANP fragments of different potencies exert their biological activities that correlate with ANP-induced CGMP increases (37). Together, these findings suggest the significance of cyclic GMP as a second messenger and a biological marker of ANP. Blockade of the ANP-induced increase of the plasma cGMP level by MAb[KY-ANP-II], therefore, indicates the in vivo efficacy of MAb[KY-ANP-II] in this study.

Because the development and maintenance of hypertension could be the result of long-term alterations in the control of blood pressure, and ANP seems to require several days to fully develop its physiological actions (38), we repetitively administered the MAb over weeks to months, to observe chronic effects on homeostasis in blood pressure and body fluid. Weekly administrations of MAb in this study were demonstrated in experiment 3 to be capable of chronically preventing the access of ANP to its receptor(s). The decline in the plasma titer or concentration of MAb[KY-ANP-II] was comparable to the reported decline curve of purified polyclonal angiotensin II antibodies injected intravenously into rats (39) and was also in agreement with the kinetics of immunoglobulins in general (40).

There might be a possibility of producing antibodies against ANP monoclonal antibody, including antiidiotypic antibodies, during the repetitive administrations. Sege and Peterson described rabbit antiidiotypic antibodies against rat antibodies to retinol-binding protein (RBP) or to insulin, by repetitive injections of rat antibodies to rabbits (41). These antibodies were shown to compete with RBP or insulin for binding to their receptors. In our experiment, antibodies against ANP MAb might interfere with the blocking action of our MAb. In experiment 3, however, serum obtained from DOCA-salt rats in group 2A after nine administrations of MAb[KY-ANP-II] retained comparable binding ability to ${ }^{125} \mathrm{I}-\alpha$-hANP as serum obtained $1 \mathrm{wk}$ after a single injection of MAb[KY-ANP-II]. This finding rules out the argument mentioned above, even if the possible production of antibodies against our ANP MAb is not excluded.

In this study, beginning of passive immunization with MAb[KY-ANP-II] before the occurrence of hypertension accelerated the increase of blood pressure during the initial phase of hypertension and the aggravated high blood pressure was maintained throughout the observation period both in SHRSP and DOCA-salt rats. In experiment 1 , since there was no difference between blood pressure of normotensive WKY treated with MAb[KY-ANP-II] in group $1 \mathrm{C}$ and that with MAb[KY-ANP-I] in group 1D, nonspecific actions of MAbcontaining ascites to increase blood pressure are unlikely. 
Moreover, in experiment 6, we also confirmed that the administration of our control MAb, MAb[KY-ANP-I] had no significant effect on the development of hypertension in both SHRSP and DOCA-salt rats. In experiment 6-1, blood pressure of SHR-SP treated with MAb[KY-ANP-II] was significantly higher than that of untreated SHR-SP, as well as that of SHRSP treated with MAb[KY-ANP-I]. These results further support the specific effect of MAb[KY-ANP-II] to accelerate the development of hypertension.

In experiment 5, the difference of the basal plasma ANP levels between SHR-SP and WKY was $\sim 150-200 \mathrm{pg} / \mathrm{ml}$ and in another series of experiments, the difference in the basal plasma ANP levels between DOCA-salt rats and control rats 8 wk after the start of DOCA and $1 \% \mathrm{NaCl}$ administration, the same maneuver of this study, was also $\sim 200 \mathrm{pg} / \mathrm{ml}(245 \pm 63$ $\mathrm{pg} / \mathrm{ml}$ for DOCA-salt rats and $81 \pm 15 \mathrm{pg} / \mathrm{ml}$ for control rats). These findings, therefore, suggest that the increment of the plasma ANP level by $200 \mathrm{pg} / \mathrm{ml}$ above the basal level modulates blood pressure in hypertensive state. There are several reports to support this hypothesis. ANP infusion at a dose of $50 \mathrm{ng} / \mathrm{kg}$ per min, which raised the plasma ANP level from 27 to $292 \mathrm{pg} / \mathrm{ml}$, decreased mean arterial pressure from 90 to 75 $\mathrm{mmHg}$ without any change in the glomerular filtration rate (42).

Previous studies on the effect of anti-ANP antiserum on blood pressure in rats seem to be inconsistent so far. Recently, Sasaki et al. demonstrated that in anesthetized rats, the bolus administration of a rabbit polyclonal antiserum against $\alpha$ rANP raised mean blood pressure by $7 \%$ (43), whereas Naruse et al. reported no significant change in blood pressure by the administration of a polyclonal antiserum against atriopeptin I, also, in anesthetized rats (44). They examined acute effects of polyclonal antisera, which inevitably include irrelevant antibodies or other substances, in an anesthetized state, which produces the different circulating ANP level from that in a conscious state, though they did not show ANP levels in their reports. We demonstrated in this study using the specific MAb against ANP that chronic blockade of circulating ANP produced an augmented rise in blood pressure in conscious hypertensive rats, which showed higher plasma ANP levels.

The plasma cGMP level of DOCA-salt rats treated with $\mathrm{MAb}$ [KY-ANP-II] in group $2 \mathrm{~A}$ was significantly lower than that of DOCA-salt rats in group $2 \mathrm{~B}$ as shown in Table IV. In addition, the elevated plasma cyclic GMP level of SHR-SP compared with that of WKY was significantly reduced by the acute injection of MAb[KY-ANP-II] (Fig. 5). Since we observed no significant changes in the plasma cyclic GMP level of WKY by the administration of MAb[KY-ANP-II], and in another series of experiments, there was no significant change of the plasma cGMP level of SHR-SP by MAb[KY-ANP-I] injection, the observed reducing effect of MAb[KY-ANP-II] on the plasma cGMP level was due to specific blockade of elevated circulating ANP. Previous investigations have demonstrated that the nitrosovasodilators activate soluble guanylate cyclase, cause accumulation of cyclic GMP and induce relaxation of vascular smooth muscle through cGMP-dependent protein kinase activation and resultant decreased phosphorylation of myosin light chain (45). Although the coupling of cGMP increment and vasodilatation by ANP has not been fully explained, the plasma cGMP level could reflect the vasodilating activity of $\operatorname{ANP}(37,45)$. Thus, the suppression of the enhanced plasma cGMP level by MAb[KY-ANP-II] can be interpreted as the inhibition of vasodilating action of endogenous ANP at the enhanced level, which resulted in the aggravation of hypertension in our hypertensive rats.

Volume overload is considered to be one of the mechanisms in the manifestation of hypertension in DOCA-salt rats. DOCA administration causes increased sodium reabsorption in the kidney and induces salt appetite in rats (30). In this study, DOCA-salt rats showed significantly higher serum sodium concentration with a reciprocal decrease of serum potassium concentration with larger intake of $1 \% \mathrm{NaCl}$ solution, compared with control rats. Diuresis and natriuresis induced by $\mathrm{DOCA}$ and $1 \% \mathrm{NaCl}$ administration were significantly reduced by the administration of MAb[KY-ANP-II] in this study. Serum creatinine and blood urea nitrogen levels of DOCA-salt rats in both groups $2 \mathrm{~A}$ and $2 \mathrm{~B}$ were almost the same and within the normal range. Impaired diuresis and natriuresis in DOCA-salt rats in group 2A thus were not considered to be ascribed to renal dysfunction caused by a non-specific effect of MAb[KY-ANP-II] or by sustained higher blood pressure observed in DOCA-salt rats treated with MAb[KYANP-II]. There are several reports that suggest the role of ANP in diuresis and natriuresis after acute hypervolemia in rats (46). Recently, Hirth et al. demonstrated blunted diuresis and natriuresis after volume expansion by ANP MAb (47). Our results of the attenuation of exaggerated diuresis and natriuresis in DOCA-salt rats by ANP MAb further support the role of increased plasma levels of ANP in accelerating diuresis and natriuresis in volume-overloaded state. Insufficient diuresis and natriuresis and, as a consequence, possibly more expanded circulatory volume in DOCA-salt rats treated with $\mathrm{MAb}[\mathrm{KY}$-ANP-II] might be associated with the acceleration of hypertension in these rats, though we have not measured extracellular fluid volume in the present study.

In experiment 1 , we could observe no significant difference in urine volume or urinary excretion of sodium in SHR-SP and WKY, though some reports show the pressure-induced diuresis and natriuresis in SHR (21). The reason for such disparity is not clear at present, but it may result from substrain differences or animal ages. During the developmental phase of hypertension, plasma volume and blood volume of SHR-SP are reported to be reduced compared with age-matched WKY (48). Lack of influence of MAb[KY-ANP-II] on urine volume or urinary excretion of sodium in SHR-SP might be, therefore, due to contracted or, at least, not increased body fluid volume in SHR-SP. The enhancing effect of ANP MAb on blood pressure in SHR-SP observed in this study, therefore, may be mainly attributed to the further increase of peripheral resistance, which is reported to be elevated in SHR (49), by the possible inhibition of vasodilating actions of endogenous ANP with ANP MAb.

After the submission of our manuscript, Needleman's group reported the effect of autoimmunization with ANP in SHR on the development of hypertension (50). They failed to detect any alteration in the increase of blood pressure of autoimmune SHR sensitized against ANP, compared with nonimmune SHR. The exact cause of the difference between our results and theirs is not clear at present. It may be accounted for by the difference of SHR substrain or by the difference in the experimental protocol. As we previously reported $(14,19$, 20), biosynthesis and secretion of ANP in SHR-SP with a severer form of hypertension are more augmented than those in SHR. Therefore, we adopted SHR-SP in our experiment. It is 
also possible that the different experimental procedures might have resulted in the different results. Because they immunized SHR with ANP during their observation period to produce ANP autoantibodies, it was not clear whether the sufficient titer of the antibodies in plasma was maintained in the developmental phase of hypertension. In addition, because their ANP autoantibodies were polyclonal, their binding affinity for ANP and recognition site must have been heterogenous. In the present study, we repetitively administered the MAb against ANP, which was homogenous in epitope recognition and binding affinity and demonstrated to antagonize the biological activity of ANP, before and during the occurrence of hypertension. We also confirmed the significant suppression of the enhanced plasma levels of cGMP in our hypertensive rats by ANP MAb.

In conclusion, this study demonstrated that chronic repetitive administrations of the MAb against $\alpha$-rANP accelerated the development of hypertension in two animal models of hypertension, SHR-SP and DOCA-salt rats. These findings support the compensatory role of augmented secretion of ANP in these hypertensive animals and suggest that increased secretion of ANP could represent one of the antihypertensive deterrent mechanisms.

\section{Acknowledgments}

The authors express cordial thanks to Ms. Hiroko Fumon and Ms. Atsuko Furu for their secretarial assistance.

This work was supported in part by research grants from the Japanese Ministry of Education, Science, and Culture; the Japanese Ministry of Health and Welfare "Disorders of Adrenal Hormone" Research Committee, Japan, 1987; Life Science Research Project of Institute of Physical and Chemical Research (RIKEN); Japan Tobacco, Inc.; Yamanouchi Foundation for Research on Metabolic Disorders; and by research grants for cardiovascular diseases (60A-3) and (62 $\left.\mathrm{A}^{\prime}-1\right)$ from the Japanese Ministry of Health and Welfare.

\section{References}

1. De Bold, A. J., H. B. Borenstein, A. T. Veress, and H. Sonnenberg. 1981. A rapid and potent natriuretic response to intravenous injection of atrial myocardial extract in rats. Life Sci. 28:89-94.

2. Kangawa, K., and H. Matsuo. 1984. Purification and complete amino acid sequence of $\alpha$-human atrial natriuretic polypeptide. Biochem. Biophys. Res. Commun. 118:131-139.

3. Needleman, P., S. P. Adams, B. R. Cole, M. G. Currie, D. M. Geller, M. L. Michener, C. B. Saper, D. Schwartz, and D. G. Standaert. 1985. Atriopeptins as cardiac hormones. Hypertension (Baltimore). 7:469-498.

4. Cantin, M., and J. Genest. 1985. The heart and the atrial natriuretic factor. Endocr. Rev. 6:107-127.

5. Sugawara, A., K. Nakao, N. Morii, M. Sakamoto, M. Suda, M. Shimokura, Y. Kiso, M. Kihara, Y. Yamori, K. Nishimura, J. Soneda, T. Ban, and H. Imura. 1985. $\alpha$-Human atrial natriuretic polypeptide is released from the heart and circulates in the body. Biochem. Biophys. Res. Commun. 129:439-446.

6. Lang, R. E., H. Thoelken, D. Ganten, F. C. Luft, H. Ruskoaho, and T. H. Unger. 1985. Atrial natriuretic factor is a circulating hormone, stimulated by volume loading. Nature (Lond.). 314:264-266.

7. Itoh, H., K. Nakao, T. Yamada, N. Morii, A. Sugawara, S. Shiono, Y. Saito, M. Mukoyama, H. Arai, G. Katsuura, M. Eigyo, A. Matsushita, and H. Imura. 1987. Modulatory role of vasopressin in secretion of atrial natriuretic polypeptide in conscious rats. Endocrinology. 120:2186-2188.

8. Sugawara, A., K. Nakao, N. Morii, M. Sakamoto, K. Horii, M.
Shimokura, Y. Kiso, K. Nishimura, T. Ban, M. Kihara, Y. Yamori, K. Kangawa, H. Matsuo, and H. Imura. 1986. Significance of $\alpha$-human atrial natriuretic polypeptide as a hormone in man. Hypertension (Baltimore). 8(Suppl. I):I-151-I-155.

9. Itoh, H., K. Nakao, M. Mukoyama, A. Sugawara, Y. Saito, N. Morii, T. Yamada, S. Shiono, H. Arai, and H. Imura. 1988. Secretion of $\mathrm{N}$-terminal fragment of $\boldsymbol{\gamma}$-human atrial natriuretic polypeptide. Hypertension (Baltimore). 11(Suppl. I):I-57-I-61.

10. Itoh, H., K. Nakao, A. Sugawara, Y. Saito, M. Mukoyama, N. Morii, T. Yamada, S. Shiono, H. Arai, K. Hosoda, and H. Imura. 1988. $\gamma$-Atrial natriuretic polypeptide $(\gamma$-ANP)-derived peptides in human plasma: co-secretion of N-terminal $\gamma$-ANP fragment and $\alpha$-ANP. J. Clin. Endocrinol. \& Metab. 67:429-437.

11. Saito, Y., K. Nakao, K. Nishimura, A. Sugawara, K. Okumura, K. Obata, R. Sonoda, T. Ban, H. Yasue, and H. Imura. 1987. Clinical application of atrial natriuretic polypeptide to patients with congestive heart failure: beneficial effects on left ventricular function. Circulation. 76:115-124.

12. Sugawara, A., K. Nakao, M. Sakamoto, N. Morii, T. Yamada, H. Itoh, S. Shiono, and H. Imura. 1985. Plasma concentration of atrial natriuretic polypeptide in essential hypertension. Lancet. ii:14261427.

13. Sugawara, A., K. Nakao, T. Kono, N. Morii, T. Yamada, H. Itoh, S. Shiono, Y. Saito, M. Mukoyama, H. Arai, and H. Imura. 1988. Atrial natriuretic polypeptide in essential hypertension and adrenal disorders. Hypertension (Baltimore). 11(Suppl. I):I-212-I-216.

14. Morii, N., K. Nakao, M. Kihara, A. Sugawara, M. Sakamoto, Y. Yamori, and H. Imura. 1986. Decreased content in left atrium and increased plasma concentration of atrial natriuretic polypeptide in spontaneously hypertensive rats (SHR) and SHR stroke-prone. Biochem. Biophys. Res. Commun. 135:74-81.

15. Imada, T., R. Takayanagi, and T. Inagami. 1985. Changes in the content of atrial natriuretic factor with the progression of hypertension in spontaneously hypertensive rats. Biochem. Biophys. Res. Commun. 133:759-765.

16. Gutkowska, J., K. Horky, C. Lachance, K. Racz, R. Garcia, G. Thibault, O. Kuchel, J. Genest, and M. Cantin. 1986. Atrial natriuretic factor in spontaneously hypertensive rats. Hypertension (Baltimore). 8(Suppl. I):I-137-I-140.

17. Sakamoto, M., K. Nakao, A. Sugawara, N. Morii, Y. Saito, H. Itoh, T. Yamada, S. Shiono, M. Shimokura, Y. Kiso, M. Kihara, Y. Yamori, and H. Imura. 1986. Effect of DOCA and salt loading on atrial and plasma levels of atrial natriuretic polypeptide. In Peptide Chemistry. Y. Kiso, editor. Protein Research Foundation, Osaka, Japan. 373-378.

18. Sugimoto, T., M. Ishii, Y. Hirata, H. Matsuoka, T. Sugimoto, A. Miyata, T. Toshimori, H. Masuda, K. Kangawa, and H. Matsuo. 1986. Increased release of atrial natriuretic polypeptides in rats with DOCA-salt hypertension. Life Sci. 38:1351-1358.

19. Arai, H., K. Nakao, Y. Saito, N. Morii, A. Sugawara, T. Yamada, H. Itoh, S. Shiono, M. Mukoyama, H. Ohkubo, S. Nakanishi, and H. Imura. 1988. Augmented expression of atrial natriuretic polypeptide (ANP) gene in ventricles of spontaneously hypertensive rats (SHR) and SHR-stroke prone. Circ. Res. 62:926-930.

20. Arai, H., K. Nakao, Y. Saito, N. Morii, A. Sugawara, T. Yamada, H. Itoh, S. Shiono, M. Mukoyama, H. Ohkubo, S. Nakanishi, and $H$. Imura. 1987. Simultaneous measurement of atrial natriuretic polypeptide (ANP) messenger RNA and ANP in rat heart. Evidence for a preferentially increased synthesis and secretion of ANP in left atrium of spontaneously hypertensive rats (SHR). Biochem. Biophys. Res. Commun. 148:239-245.

21. Garcia, R., G. Thibault, J. Gutkowska, K. Horky, P. Hamet, M. Cantin, and J. Genest. 1985. Chronic infusion of low doses of atrial natriuretic factor (ANF Arg 101-Tyr 126) reduces blood pressure in conscious SHR without apparent changes in sodium excretion. Proc. Soc. Exp. Biol. Med. 179:396-401.

22. Yasujima, M., K. Abe, M. Kohzuki, M. Tanno, Y. Kasai, M. Sato, K. Omata, K. Kudo, K. Tsunoda, K. Takeuchi, K. Yoshinaga, 
and T. Inagami. 1985. Atrial natriuretic factor inhibits the hypertension induced by chronic infusion of norepinephrine in conscious rats. Circ. Res. 57:470-474.

23. Richards, A. M., M. G. Nicholls, E. A. Espiner, H. Ikram, T. G. Yandle, S. L. Joyce, and M. M. Cullens. 1985. Effects of $\alpha$-human atrial natriuretic peptide in essential hypertension. Hypertension (Baltimore). 7:812-817.

24. Morii, N., K. Nakao, A. Sugawara, Y. Saito, H. Itoh, T. Yamada, S. Shiono, M. Mukoyama, H. Arai, and H. Imura. 1988. Atrial natriuretic polypeptide (ANP) in essential hypertension and aldosteronism. Pharmacokinetics and effects on renal cardiovascular and endocrine systems. In Biologically Active Atrial Peptide. American Society of Hypertension Symposium Series Vol. 2. B. M. Brenner and J. H. Laragh, editors. Raven Press, New York. 559-564.

25. Mukoyama, M., K. Nakao, H. Sugawa, N. Morii, A. Sugawara, T. Yamada, H. Itoh, S. Shiono, Y. Saito, H. Arai, T. Mori, H. Yamada, Y. Sano, and H. Imura. 1988. A monoclonal antibody to $\alpha$-human atrial natriuretic polypeptide. Hypertension (Baltimore). 12:117-121.

26. Mukoyama, M., K. Nakao, T. Yamada, H. Itoh, A. Sugawara, Y. Saito, H. Arai, K. Hosoda, G. Shirakami, N. Morii, S. Shiono, and H. Imura. 1988. A monoclonal antibody against $\mathrm{N}$-terminus of $\alpha$-atrial natriuretic polypeptide ( $\alpha$-ANP): a useful tool for preferential detection of naturally circulating ANP. Biochem. Biophys. Res. Commun. 151:1277-1284.

27. Schwartz, D., D. M. Geller, P. T. Manning, N. R. Siegel, K. F. Fok, C. E. Smith, and P. Needleman. 1985. Ser-Leu-Arg-Arg-atriopeptin III: the major circulating form of atrial peptide. Science (Wash. DC). 229:397-400.

28. Nakao, K., A. Sugawara, S. Shiono, Y. Saito, N. Morii, T. Yamada, H. Itoh, M. Mukoyama, H. Arai, M. Sakamoto, and H. Imura. 1987. Secretory form of atrial natriuretic polypeptide as cardiac hormone in humans and rats. Can. J. Physiol. Pharmacol. 65:17561761.

29. Itoh, H., K. Nakao, N. Morii, T. Yamada, S. Shiono, M. Sakamoto, A. Sugawara, Y. Saito, G. Katsuura, T. Shiomi, M. Eigyo, A. Matsushita, and H. Imura. 1986. Central action of atrial natriuretic polypeptide on blood pressure in conscious rats. Brain Res. Bull. 16:745-749.

30. Itoh, H., K. Nakao, G. Katsuura, N. Morii, S. Shiono, M. Sakamoto, A. Sugawara, T. Yamada, Y. Saito, A. Matsushita, and H. Imura. 1986. Centrally infused atrial natriuretic polypeptide attenuates exaggerated salt appetite in spontaneously hypertensive rats. Circ. Res. 59:342-347.

31. Nakao, K., A. Sugawara, N. Morii, M. Sakamoto, M. Suda, J. Soneda, T. Ban, M. Kihara, Y. Yamori, M. Shimokura, Y. Kiso, and H. Imura. 1984. Radioimmunoassay for $\alpha$-human and rat atrial natriuretic polypeptide. Biochem. Biophys. Res. Commun. 124:815-821.

32. Steiner, A. L., C. W. Parker, and D. M. Kipnis. 1972. Preparation of antibodies and iodinated cyclic nucleotides. J. Biol. Chem. 247:1106-1113.

33. Wallenstein, S., C. L. Zucker, and J. L. Fleiss. 1980. Some statistical methods useful in circulation research. Circ. Res. 47:1-9.

34. Mohring, J., M. Petri, M. Szokol, D. Haack, and B. Mohring. 1976. Effects of saline drinking on malignant course of renal hypertension in rats. Am. J. Physiol. 230:849-857.

35. Manning, P. T., D. Schwartz, N. C. Katsube, S. W. Holmberg, and P. Needleman. 1985. Vasopressin-stimulated release of atriopeptin: endocrine antagonism in fluid homeostasis. Science (Wash. DC). 229:395-397.

36. Waldman, S. A., R. Rapoport, and F. Murad. 1984. Atrial natriuretic factor selectively activates particulate guanylate cyclase and elevates cyclic GMP in rat tissues. J. Biol. Chem. 259:14332-14334.

37. Hamet, P., J. Tremblay, S. C. Pang, R. Skuherska, E. L. Schiffrin, R. Garcia, M. Cantin, J. Genest, R. Palmour, F. R. Erwin, S. Martin, and R. Goldwater. 1986. Cyclic GMP as mediator and biological marker of atrial natriuretic factor. J. Hypertens. 4(Suppl. 2):S49S56.

38. Trippodo, N. 1987. An update of the physiology of atrial natriuretic factor. Hypertension (Baltimore). 10(Suppl. I):I-122-I-127.

39. Oster, P., H. Bauknecht, and E. Hackenthal. 1975. Active and passive immunization against angiotensin II in the rat and rabbit. Evidence for a normal regulation of the renin-angiotensin system. Circ. Res. 37:607-614.

40. Schultze, H. E., and J. H. Heremans. 1966. Molecular Biology of Human Proteins. Elsevier Publishing Company, Amsterdam. 451-511.

41. Sege, K., and P. A. Peterson. 1978. Use of anti-idiotypic antibodies as cell-surface receptor probes. Proc. Natl. Acad. Sci. USA 75:2443-2447.

42. Granger, J. P., T. J. Opgenorth, J. Salazar, G. Romero, and J. C. Burnett, Jr. 1986. Long-term hypotensive and renal effects of atrial natriuretic peptide. Hypertension (Baltimore). 8(Suppl. II):II-112-II116.

43. Sasaki, A., O. Kida, J. Kato, S. Nakamura, K. Kodama, A. Miyata, K. Kangawa, H. Matsuo, and K. Tanaka. 1987. Effects of antiserum against $\alpha$-rat atrial natriuretic peptide in anesthetized rats. Hypertension (Baltimore). 10:308-312.

44. Naruse, M., K. Obana, K. Naruse, N. Sugino, H. Demura, K. Shizume, and T. Inagami. 1985. Antisera to atrial natriuretic factor reduce urinary sodium excretion and increase plasma renin activity in rats. Biochem. Biophys. Res. Commun. 132:954-960.

45. Murad, F., D. C. Leitman, B. M. Bennett, C. Molina, and S. A. Waldman. 1987. Regulation of guanylate cyclase by atrial natriuretic factor and the role of cyclic GMP in vasodilation. Am. J. Med. Sci. 294:139-143.

46. Khraibi, A. A., J. P. Granger, J. C. Burnett, Jr., K. R. Walker, and F. G. Knox. 1987. Role of atrial natriuretic factor in the natriuresis of acute volume expansion. Am. J. Physiol. 252:R921-R924.

47. Hirth, C., J. P. Stasch, A. John, S. Kazda, F. Morich, D. Neuser, and S. Wohlfeil. 1986. The renal response to acute hypervolemia is caused by atrial natriuretic peptides. J. Cardiovasc. Pharmacol. 8:268-275.

48. Schomig, R. D. A., H. Haebara, J. F. E. Mann, W. Rascher, J. B. Luth, N. Grunberz, and F. Gross. 1978. Studies on the pathogenesis of spontaneous hypertensive rats. Circ. Res. 43(Suppl. I):I-98-I106.

49. Folkow, B., M. Hallback, Y. Lungren, and L. Weiss. 1970. Structurally based increase of flow resistance in spontaneously hypertensive rats. Acta Physiol. Scand. 79:373-378.

50. Greenwald, J. E., M. Sakata, M. L. Michener, S. D. Sides, and P. Needleman. 1988. Is atriopeptin a physiological or pathophysiological substance? Studies in the autoimmune rat. J. Clin. Invest. 81:1036-1041. 